\title{
Error Analysis of Business English Translation Based upon Functional Theory
}

\author{
Lili Zhang \\ Beijing Wuzi University, Beijing, China \\ Email: mywritingclass@163.com
}

Received 5 July 2016; accepted 16 July 2016; published 19 July 2016

Copyright (C) 2016 by author and Scientific Research Publishing Inc. This work is licensed under the Creative Commons Attribution International License (CC BY). http://creativecommons.org/licenses/by/4.0/ (c) (7) Open Access

\begin{abstract}
The functional theory of translation, with Skopostheorie as a core, advocates that the translation process should not only be based upon equivalence but more importantly upon the prospective functions or Skopos of the target text. Translation errors study was also put forward and carried out as a result. Based on the explanation of this translation theory, this paper makes a thorough analysis of business English translation errors, with the major reasons raised and corresponding solutions and strategies presented. Besides shedding lights on the theoretical study of translation in this field, the analysis aims to play a positive role in improving the substantial quality of business English translation in practice.
\end{abstract}

\section{Keywords}

Error Analysis, Business English Translation, Functional Theory, Skopostheorie

\section{Introduction}

Skopos, as the core theory of Functional school of translation theory, puts emphasis on translation which is considered as an activity with an aim or purpose at the target readers or audiences. It emphasizes the communicative purpose of the translation, which requires business English translators to have a clear understanding of the communicative function of the business activities. The application of the Skopos theory in the business English translation breaks many barriers of mal-communication in business and solves many language problems in the transnational business activities. At the same time, many errors also occur in this process. The following discussion, based upon functional theory, mainly focuses on its reason analysis, phenomenon analysis and corresponding strategies presentation for the translation errors in business English translation practice. 


\section{Functional Theory of Translation}

Breaking through the conventional "equilibrium” theory of the language translation, Hans Vermeer, a German translation theorist, presented the Skopostheorie which is the core of functional translation. In Greece, Skopos means "purpose". In Skopostheorie, translation shall not only focus on the parallel effect of the original passage and its translated version but the best translation should be based on the comprehensive analysis of the original passage, the purpose, prospect function and other context factors (Vermere, 2001). Hans Vermere argued that translation is an action with its aim. It is a discourse conversion that is generated in the context of the targeted language to achieve certain purposes and reach its targeted receivers. In his framework of Skopostheorie, the most important factors that determine the purpose of translation are the language receivers who will receive the translated passage. They have their own culture background, expectations towards the translation works and the need of communication. All translation activities should comply with "Skopos rule" in the first place by Skopostheorie, which means that translation should be generated in the way expected by the receivers in the context of target language and its culture (Nord, 2001). The purpose of translating determines its process. In other words, the ends determine means. The coherence rule means that the translation must live up to the standard of intra-lingual coherence, or that it must be readable and acceptable so that it can be understood by its receivers and makes sense in both the culture and particular communication context. The fidelity rule means that inter-lingual coherence should be made between the original material and its translation. The fidelity rule is similar to the so-called faithfulness in other translation theories. However, to which extent and in what form the translation should be faithful to the original material depends both on the purpose of translation and on the translator's understanding about the original material.

\section{Reason Analysis of Business English Translation Errors}

Business English is a language used specifically on the inter-communication background, and it serves as a variant of English language on social function. The various and miscellaneous activities of international business determines its complexity, particularity and diversity. Business English presents a series of special features in vocabulary, grammar, lexis, syntax and structure. Therefore, the translation of business English is not an easy work to do, and it is a challenging job to make its translation accurate, appropriate, and coherent as well. Vocabularies in business English translation are substantial and practical; various forms of discourse have its own specific requirement towards the formality, preciseness and creativity of the vocabularies. Besides, it also has a significant amount of specialized vocabulary and terms, abbreviations. The greater features in Business English are its conciseness and logic in statements. Without a doubt, all these factors should be taken into careful consideration, and different techniques are required to realize the effect of loyalty, coherence and appropriateness in translation (Weng, 2013).

The Skopostheorie in functional translation plays a very significant role in business English translation. It can serve as not only a theoretical guidance for translators but also the ultimate principle of translation practice (Fan, 2005). It determines the right choice of methods and strategies in business English translation. To comply with the three major rules of Skopostheorie, i.e. skopos, coherence and fidelity, and to tailor to the specific features of business English, the translation practice is put into a challenging situation full of great complexity and delicacy. It therefore is inevitable to bring up all kinds of errors in translation, which will seriously affect the real communication in many business situations.

\section{Business English Translation Errors and Corresponding Solutions}

According to the Skopostheorie in Functional School, the purpose of translation is to realize the function of serving the expected readers. Therefore any methods or results that prevent it from happening are translation errors. That is to say, if the methods or strategies adopted by the translator can do some help to realize the expected function and purpose in target language in target communication environment, that translation is considered as being good. Otherwise, translation errors happen. From different levels, all the translation errors can be summarized as the following three major types: linguistic translation errors, cultural translation errors and pragmatic translation errors (Wang, 2013).

\subsection{Linguistic Translation Errors}

Linguistic translation errors are a specific level of translation errors. It mainly embodies in vocabulary, grammar, 
voice, idioms and other micro-linguistics level. It can be attributed to the fact that not accurate or even wrong expressions are used in translation or the translation is constrained by the form of the original but fails to correctly reproduce the original language, finally not achieving the desired effect and expected function of the text. Business English terms are required to be accurately expressed regarding its characteristics of accuracy and preciseness. Translators are required to use the exact words and expressions to the various occasions, while it is not allowed to translate passages word to word. Besides, in business English translation, it is not wise to be confined to original forms, instead, it is advisable to comply with the English way of thinking, expression usage and inner grammatical structure. Once violating these practical rules, improper collocation or even contrary meaning was probably to arise, bringing about linguistic translation errors.

Vocabulary level: business English expressions are accurate and rigorous. The different business occasions also requires specific terms and vocabulary of accuracy and exactness. Translation theorist Nida once pointed out: in different languages, the corresponding word never has the exactly same semantic field, which requires the translator to choose the RIGHT word to express the original in translation but not always require the VERY word in equivalence of translation and the original.

Grammar level: If more energy in translation is released to stick to the original form and it does not comply with the English way of thinking, language customs and inner grammatical structure, grammar translation errors will occur.

Voice level: Confined to the traditional point of view, the business translation, especially in science and technology field, use the passive voice more than often. More passive voice application results in the top-heavy translation with clumsy structure, which not only fails to highlight the informative function, but sometimes also can bring about a syntax error. In fact, in recent years, the active voice of science and technology English is becoming more and more popular. In this case, we better conform to this trend of using more the active voice translation to make the passage more structured, focused, and semantic coherent.

\subsection{Cultural Translation Errors}

Cultural translation errors are errors brought by cultural differences in selecting language forms in communication. Due to translators' lack of understanding of the cultural background of target language, namely, the conflict of norms and practices between source language and target language, this type of errors occur. The main manifestations are: different cultural backgrounds and ways of thinking of the two languages; Chinese focuses on "ways of induction" while English focuses on "ways of deduction"; In language expression, Chinese words tend to be overdone, luxuriant and tautology is often used, while English expressions tend to be concise, lively with rigorous logic, in plain style and so on (Wang, 2013).

Therefore, the translator must acknowledge the cultural characteristics and discrepancy between the two languages. To achieve best transmission of cultural information, translators should commit to transforming the cultural connotation in an appropriate way between the bilingual cultures. Taking translation of a Chinese scientific paper as an example, we need to reconstitute the content, change the order of the sentences and put important information in the front so as to spotlight the useful message and make the translation more tailored to English culture. Otherwise, if we ignore the cultural context of the target language and the cognitive environment of the target readers, we may bring a cultural translation error, regardless of the differences between the original and the translation.

\subsection{Pragmatic Translation Errors}

Pragmatic translation errors are the highest level of translation errors in a sense that it covers all the mistakes in business English translation. The main reason that leads to all kinds of pragmatic translation errors is that in the process of translation, translators ignore the function of target text or the audience of translation. In other words, pragmatic translation errors occur when translators fail to understand the expected readers and fail to tailor the translation to the needs of target audience. Typical pragmatic translation errors are the following: 1) The useless information to the target text in the original one is not reduced or simplified in the translation, resulting in the informative function jeopardized; 2) The useful information to the target text in the original one is deleted or simplified in the translation, resulting in the information deficiency; 3) Inflexible and inefficient word-for-word translation or literal translation; 4) Lack of necessary explanatory notes to terminology from the original text, resulting in deficiency of information sharing function. 
Therefore, in business English translation, attention should be paid to the appropriate cut or simplification of the original passage, avoiding mechanical word-for-word translation or literal translation. It is sometimes a necessity to make explanatory notes to terminology in the original passage, acting as a complement of shared information and background knowledge that are unknown by readers. Being specially audience-oriented, business English translators are required to present accurate and rigorous structure, clear and coherent sentences, proper form of translation to readers with respect to the uniqueness and diversity of business English.

\section{Conclusion}

As Paul Kussmaul writes, the functional translation has a great affinity with Skopostheorie. The function of a translation depends on the knowledge, expectations, values and norms of the target readers who are again influenced by the situation they are in and by the culture. These factors determine whether the function of the source text or passages in the source text can be preserved or have to be modified or even changed (Vermere, 2001). According to this theory, a good translation depends not only on the equivalence of original text and target text but also on the adequacy of the translation to its purposes or expected functions. This undoubtedly provides the theoretical basis and support for the error studies of business English translation. From different levels and aspects, namely, linguistic, cultural, and pragmatic, the error analysis of business English translation sheds light on major challenges and corresponding strategies of translation in this field, which is supposed to help improve the business English translation quality eventually.

\section{Funding}

This article is funded by 2015 BWU Youth Fund Project "Research and Practice of Business English Translation Based on Skopos Theory”.

\section{References}

Fan, Y. (2005). On Translation Errors in the Perspective of Skopos Theory. Journal of PLA University of Foreign Languages, No. $1,70-72$.

Nord, C. (2001). Translating as a Purposeful Activity, Functionalist Approaches Explained. Shanghai: Shanghai Foreign Language Education Press.

Vermere, H. (2001). A Framework for a General Theory of Translation. Shanghai: Shanghai Foreign Language Education Press.

Wang, X. M. (2013). An Error Study of Scientific Papers Translation Based on Skopos Theory. Northwest Medical Education, 4, 73-76.

Weng, F. X. (2013). An Approach to the 4Es Translation Criterion of Business English. Shanghai Journal of Translators, No. 1, 34-38. 


\section{Submit or recommend next manuscript to SCIRP and we will provide best service for you:}

Accepting pre-submission inquiries through Email, Facebook, LinkedIn, Twitter, etc.

A wide selection of journals (inclusive of 9 subjects, more than 200 journals)

Providing 24-hour high-quality service

User-friendly online submission system

Fair and swift peer-review system

Efficient typesetting and proofreading procedure

Display of the result of downloads and visits, as well as the number of cited articles

Maximum dissemination of your research work

Submit your manuscript at: http://papersubmission.scirp.org/ 